\title{
An Input-Output Ex Ante Regional Model to Assess the Short- Term Net Effects of the 16 April 2016 Earthquake in Ecuador
}

\author{
Jorge Salgado $^{1} \cdot$ José Ramírez-Álvarez $^{1} \cdot$ Diego Mancheno ${ }^{1}$
}

Accepted: 28 April 2021/Published online: 2 June 2021

(C) The Author(s) 2021

\begin{abstract}
The 16 April 2016 earthquake in Ecuador exposed the significant weaknesses concerning the methodological designs to compute-from an economic standpoint - the consequences of a natural hazard-related disaster for productive exchanges and the accumulation of capital in Ecuador. This study addressed one of these challenges with an innovative ex ante model to measure the partial and net short-term effects of a natural hazard-related catastrophe from an interregional perspective, with the 16 April 2016 earthquake serving as a case study. In general, the specified and estimated model follows the approach of the extended Miyazawa model, which endogenizes consumption demand in a standard input-output model with the subnational interrelations and resulting multipliers. Due to the country's limitations in its regional account records the input-output matrices for each province of Ecuador had to be estimated, which then allowed transactions carried out between any two sectors within or outside a given province to be identified by means of the RAS method. The estimations provide evidence that the net short-term impact on the national accounts was not significant, and under some of the simulated scenarios, based on the official information with respect to earthquake management, the impact may even have had a positive effect on the growth of the national product during 2016.
\end{abstract}

Keywords Earthquake impact - Ecuador · Inputoutput $\cdot$ RAS method $\cdot$ Regional model

Jorge Salgado

jasalgado@puce.edu.ec

1 Faculty of Economics, Pontificia Universidad Católica del Ecuador, 17012184 Quito, Pichincha, Ecuador

\section{Introduction}

The 16 April 2016 earthquake in Ecuador, which had its epicenter in the coastal province of Manabí, revealed significant lags in the methodology to calculate, from an economic standpoint, the consequences of a natural hazardrelated disaster for productive exchanges and the accumulation of capital in Ecuador. Inaccuracies related to calculations and theoretical understanding among policymakers and their technicians could even be seen with respect to the identification and differentiation of direct or first-order effects ${ }^{1}$ (loss of equipment, productive infrastructure, or capital accumulation involved in the productive process) and indirect or higher-order effects (those reflected in changes in economic flows as a result of exogenous natural or human shocks) resulting from the earthquake (La Hora 2016; El Telégrafo 2016).

The instrumental and conceptual limitations are explained by two facts. First, there is the temporal distance between the most recent similar events. According to Ye et al. (2016) and Chunga et al. (2016), the central Ecuadorian coast experienced five earthquakes with similar magnitudes and tectonic origins in the 120 years prior to 2016: 1896, 1906, 1942, 1956, and 1998. Incidents with epicenters in other regions of Ecuador, with significant magnitudes during the same period, include Ambato in 1949, Reventador in $1987,{ }^{2}$ Pomasqui in 1990, and Pujlí in 1996 (Beauval et al. 2010). The Reventador earthquake, with a magnitude of $7.1 \mathrm{Mw}$, claimed approximately 1,000 victims, resulted in 5,000 refugees, and damaged the TransEcuadorian Pipeline, the country's main oil infrastructure at that time (Bolton 1991). In the view of experts and the

\footnotetext{
1 As per the categories proposed by Rose (2004).

2 In 1976, this area was also affected by a volcanic eruption.
} 
media, this event was the closest comparable scenario to the 16 April 2016 event, mainly due to its immediate socioeconomic repercussions.

Second, according to Ellison et al. (1984), the short- and long-term specialized research in the theoretical and empirical modeling of the economic implications of an earthquake began 50 years ago. They identified some works of the initial stage in this field: Dacy and Kunreuther (1969), Cochrane (1974), National Academy of Sciences (1975), Haas et al. (1977), Friesma et al. (1979), Wright et al. (1979), Wright and Rossi (1981), and Munroe and Ballard (1983). Ellison et al. (1984) also pointed out some technical deficiencies motivated by the following reasons: the low number of previous studies that makes difficult a generalization; the absence of a contrafactual to make viable an impact evaluation; some limitations in the measuring modelization of the short run, mainly around inputoutput models; the lack of long-term measurement; and confusion between flow and stock concepts-as it happened in Ecuador during the 2016 earthquake.

Okuyama and Chang (2004) illustrated that throughout the 1990s interest and the number of publications increased as a result of the $42 / 169$ resolution by the United Nations General Assembly in $1987,{ }^{3}$ which designated the 1990 s as the International Decade for Natural Disaster Reduction. Significant natural hazard-related disasters also occurred that promoted the interest of researchers - the 1992 Hurricane Andrew destroyed Miami's residential areas; the 1995 Hanshin earthquake affected a significant part of the industrial infrastructure located in the city of Kobe; and the 1999 Chi-Chi earthquake in Taiwan had an impact on the global production of semiconductors (Scawthorn et al. 1997; National Research Council 1999; Chang 2000).

The production of Latin American research literature was led by the Economic Commission for Latin America and the Caribbean (ECLAC). This, however, included research that did not contain considerations for theory, nor were these studies concerned with quantitative modeling. These investigations focused on the systematization of official information. As with the global trend, document development by the ECLAC (1973) began in the 1970s with a first report on the 1972 earthquake in the city of Managua. This development was revitalized in the 1980s and 1990s with studies that analyzed the effects of: (1) cyclones in Central America; (2) the El Niño phenomenon in the Andes; and (3) earthquakes in various countries of the region (Zapata et al. 2000). ${ }^{4}$

\footnotetext{
3 https://digitallibrary.un.org/record/152704? $1 \mathrm{n}=\mathrm{en}$.

${ }^{4}$ Zapata et al. (2000) put forward a summary of the studies prepared by the Commission to quantify the economic effects of natural hazards and disasters, from 1972 through 1999, which differentiated direct effects from indirect effects, and provided an analysis of the repercussions on the balance of payments.
}

Based on these efforts, and particularly on the processes used for the socioeconomic analysis of the impacts of disasters on Mexico, Meli et al. (2005) and Bitrán (2009) proposed a methodology to evaluate the socioeconomic impacts of disasters, which constitutes a frame of reference for immediate analysis that is useful specifically for the Latin-American context. It includes field visits and procedures for data collection and their systematization (it could be understood as a quantitative-qualitative approach). The data are obtained mainly from national government agencies and official institutions in charge of facing crises. It is an ex post methodology to address the impact of an earthquake on economic stocks and flows.

For Ecuador, the documents published by the Commission were aimed at analyzing the El Niño phenomena of the 1982-1983 and 1997-1998 periods, and the impact of the 1987 Reventador earthquake. With respect to the analysis of the effects of the 2016 earthquake, the Commission was involved in the initial official assessment of direct losses (National Secretariat for Planning and Development 2016). More recent studies on the socioeconomic implications of catastrophes by other research institutions already address the effects of the 16 April 2016 earthquake. Carrión et al. (2017) compiled a series of case studies, without a focus on macroeconomics, and Toulkeridis et al. (2017) put forward a proposal based on extrapolating parameters from events relating to other economies, the historical analysis of insurance services for natural hazard-related disasters, and the initial information published by government agencies regarding the earthquake supported by the Commission.

Both the ECLAC documents and the most recent national research literature have focused on the economic dimension mainly through ex post descriptive exercises using official information, and extrapolating parameters from other contexts, with their obvious limitations. From an ex post analysis standpoint, explaining the short-term effects on macroeconomic flows, based on a comparison of annual differences in production levels, does not allow the effects of the initial shock of an event to be isolated or differentiated with respect to subsequent aid-related events. It also does not provide insight into the immediate subregional and sectoral effects of a natural hazard-related catastrophe on a specific place of a given economy. Avelino (2017) and Avelino and Hewings (2017) provide a broad discussion of the temporal implications in the impact evaluation.

Our study addressed these challenges with an innovative ex ante model to measure-in the Ecuadorian and LatinAmerican context - the partial and net short-term effects of a natural hazard-related catastrophe from an interregional perspective for the earthquake on 16 April 2016. In general, the specified and estimated model follows the 
approach of the extended Miyazawa model, as presented by Okuyama (2004), which endogenizes consumption demand in a standard input-output model with the subnational interrelations and resulting multipliers. Galbusera and Giannopoulos (2018) highlight that input-output methodologies and their extensions have increasingly been used as techniques for measuring and counteracting disasters, assuming the complexity of the economy (for example, cascading economic effects of disasters). It is important to note that the backward and forward linkages represented by these models allow the identification of key sectors and regions.

Due to the limitations of the country's regional accounts, the input-output matrices for each province had to be estimated-in order to identify the transactions carried out between any two sectors within or outside a given province-using the RAS ${ }^{5}$ method proposed by Stone and Brown (1962). This approach was also employed to estimate the household final consumption by province, as it had only been estimated at the national level. In some countries like Ecuador, the simultaneous use of RAS matrix and the extended Miyazawa model could give insights into how to deal with data limitations, opening the possibilities of ex ante modeling in contexts with high risks of natural hazard-related disasters and weak national account systems.

The results obtained are consistent with the investigations of Albala-Bertrand (1993), Okuyama et al. (1999), Tol and Leek (1999), Skidmore and Toya (2002), and Loayza et al. (2012), provide evidence that the short-term net impact on national accounts was not significant, and under some of the simulated scenarios, may even have had a positive effect on national product growth during 2016. With respect to the literature, which has used input-output approaches for addressing natural hazard and disaster effects, the findings obtained and the methodology are close to Yu et al. (2013) and Wu et al. (2012). Both provide spatial and sectoral insights and guidelines to build effective government support policies after an earthquake.

Section 2 outlines some economic facts related to Ecuador from a geographical point of view. Section 3 supports and formalizes analytically the methodology, and Sect. 4 presents the main results of the estimation of the ex ante model for the 16 April 2016 earthquake. The article

\footnotetext{
5 The RAS method is a bi-proportional adjustment technique developed by Stone and Brown (1962) for the adjustment, balance, and updating of the Input-Output tables. It gets its name from the iterative multiplication of three matrices. A diagonal matrix $R$ of row multipliers, a matrix $A$ whose row and column totals must be equal to the desired ones, and a diagonal matrix $S$ of column multipliers. Mathematically, the RAS method is equivalent to a maximum crossentropy problem, which minimizes the differences of a matrix with respect to external sources of information, subject to consistency restrictions in rows and columns.
}

concludes with suggestions for the next steps in the field of ex ante disaster research for the Ecuadorian context, which is characterized by the highest risks and vulnerabilities related to natural events in the world.

\section{Economic Structure of Ecuador}

Ecuador is located on the Pacific coast of South America and borders Colombia to the north and Peru to the south and southeast. The Galapagos Islands are part of its territorial space. It has $248,360 \mathrm{~km}^{2}$ of extension and is crossed by the equator. Its continental area includes three regions: the coast, the mountains, and the Amazonian region. Ecuador is one of the most densely populated countries in Latin America with 16.3 million inhabitants and a GDP of USD 92,042 million in 2015. The country's GDP per capita is approximately USD 6,100 in current values of 2015 (CBE 2020), which places it within the middle-income countries. $^{6}$

The country is administratively organized in 24 provinces. One of the most important, from a cultural and historical point of view, is the coastal province of Manabí where the epicenter of the 16 April 2016 earthquake was located. With $9.2 \%$ of the population, Manabí is the third most populated province after Guayas $(23 \%)$ to the south and Pichincha (18\%) to the east. Manabí is also the province with the third highest income after Pichincha (27.5\%) and Guayas (26.5\%), with a Gross Value Added (GVA) that represents $6.08 \%$ of the national total (CBE 2020) (Fig. 1).

The productive structure of Ecuador is regionally characterized by 16 economic activities, according to the first digit of the International Standard Industrial Classification of All Economic Activities (ISIC). There are four industries that each contributed more than $10 \%$ to the GVA in 2015: manufacturing (15.6\%), construction (12.1\%), wholesale and retail trade $(11.1 \%)$, and agriculture, forestry, and fishing (10.2\%). In these activities, Manabí contributed $1.4 \%, 1.2 \%, 1 \%$, and $0.7 \%$, respectively. It means that Manabí's relative contribution to the GVA is not significant (CBE 2020) (Fig. 2).

Ecuador's economic spatial setup is characterized by only a few provinces that specialize in more than 18 activities of a total of 46 following the ISIC (Fig. 3). Most of the provinces are specialized in fewer activities. Manabí is only specialized in agriculture, forestry, and fishing

\footnotetext{
${ }^{6}$ According to the Central Bank of Ecuador, the country's GDP grew at an average annual rate of $4.3 \%$ between 2010 and 2015 . Within this period, 2015 was the year with the lowest growth rate of $0.1 \%$, due to the international crisis caused by the fall in oil prices, the depreciation of the currencies of neighboring countries, and the appreciation of the US dollar (legal tender in Ecuador since 2000).
} 


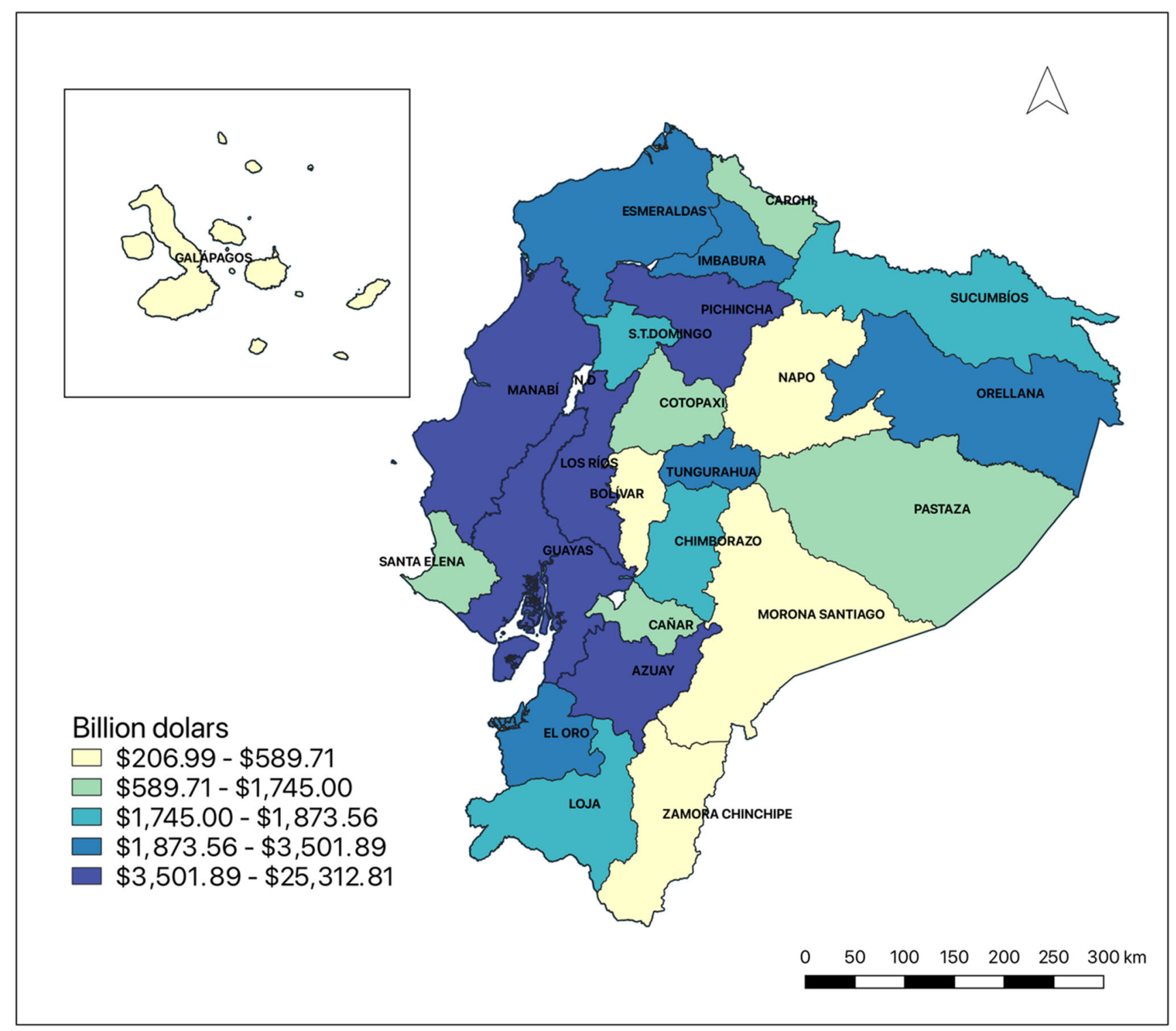

Fig. 1 Gross Value Added for Ecuador's provinces in 2015. Data Source (CBE 2020)

activities as well as retail trade activities. By contrast Pichincha, Guayas, and Azuay concentrate most of the activities developed in the country, reflecting a kind of center-periphery spatial structure. This configuration is essential to evaluate the net effect of the earthquake on the economy because the negative effect or the negative multiplier in the whole economy is assumed to be bigger if the epicenter is located in diverse areas rather than in areas with simple economic characteristics.

\section{Methodology}

This section explains the methodology used to compute the high-order effects of the 2016 earthquake in Ecuador. The approach used in this study is justified by its strengths and versatility, especially for a highly correlated economic system-regional and sectoral—such as Ecuador, with strong data limitations. The section includes a formal description of the extended Miyazawa input-output model used for the estimation of the earthquake effects and the extensions of the RAS method-analytically expressedthat are employed to compute the data required by the extended input-output model that are not offered by the national accounts system. The simultaneous application of these approaches allows us to establish a baseline and to 


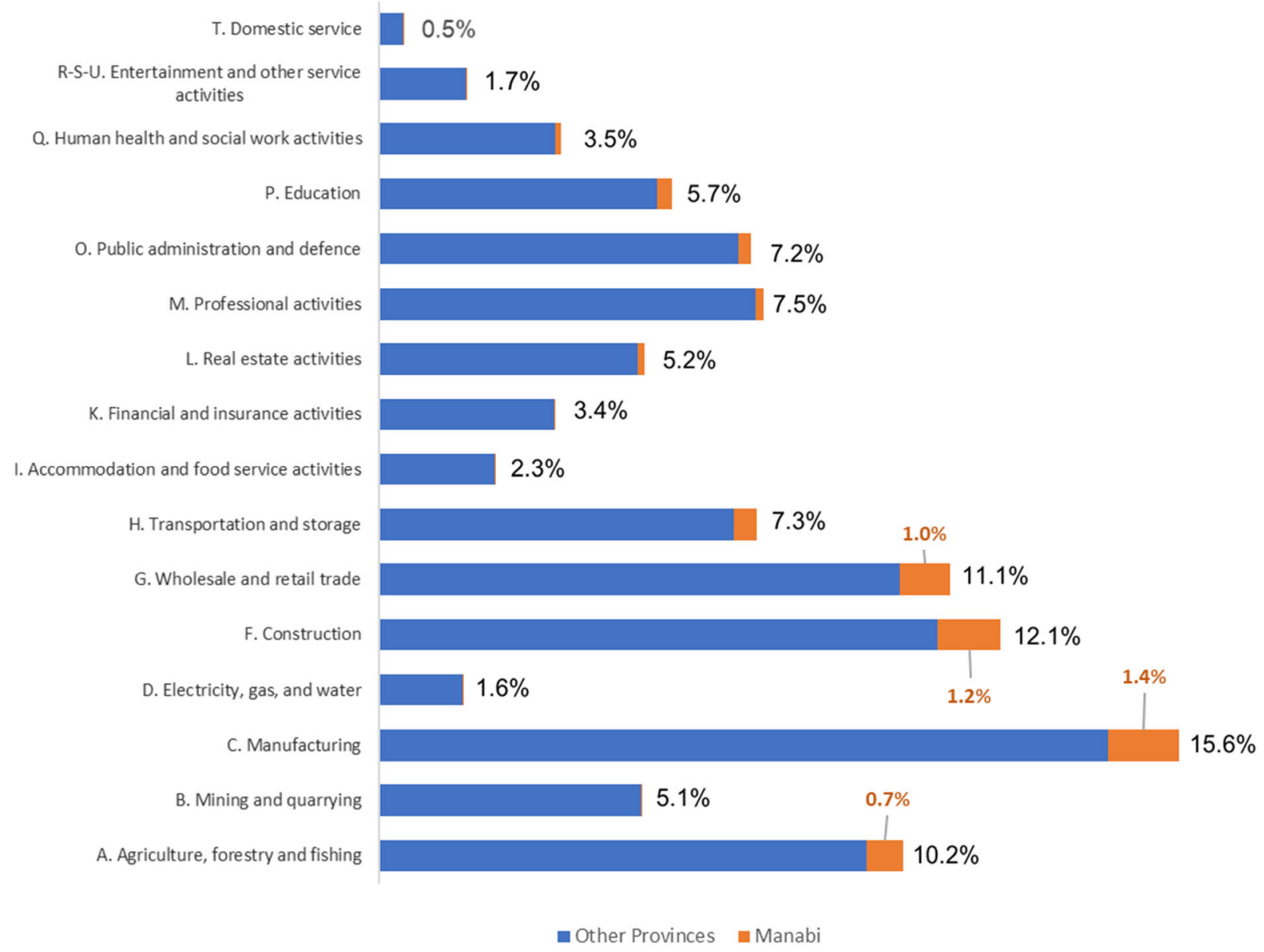

Fig. 2 Percentage of Gross Value Added by Ecuador's industries in 2015, according to the first digit of the International Standard Industrial Classification (ISIC). Data Source (CBE 2020)

simulate the negative effects of the earthquake shock and the effect of government actions within the economy.

\subsection{Justification of the Model}

According to Avelino and Hewings (2017), Oosterhaven and Bouwmeester (2016), and Okuyama (2008), there are three types of techniques to compute the higher- or indirect-order effects caused by a natural hazard-related catastrophe: (1) input-output models; (2) general equilibrium models; and (3) econometrics. The first two are micro-founded macroeconomic models for ex ante evaluation, and econometric models are used generally for ex post evaluation. Here, the prevailing strategies are those based on macroeconomic modeling, unlike strategies aimed at analyzing direct or first-order effects, where geographic information systems have been used as well as other methodologies that involve visiting the areas (Rose 2004).

Most research on higher-order effects makes use of input-output models and their extensions. The straightforward lineal structure needed for modeling, the reasonable requirements of information, and the versatility to compute sectoral and regional multipliers make these models an effective strategy for short-term analysis (Okuyama 2008). Their mathematical formalization is based on three basic assumptions: Marx-Leontief technologies, no capacity constraints, and perfect inelastic demands. ${ }^{7}$ These characteristics make this approach the most suitable for an ex ante estimation for Ecuador, especially due to data limitations.

\footnotetext{
7 These assumptions imply that the demand for commodities is determined as a fixed proportion of output, regardless of the price of the input. This feature is admissible in the short term, since the substitution between commodities is rare in a production process without technological changes. To eliminate this assumption and perform a robustness analysis, a CES (constant elasticity of substitution) technology can be specified. However, the estimation of an elasticity of substitution is required. Estimating this elasticity is difficult, since it involves a panel of data on the demand for commodities and their prices over time, which was not available for the present investigation.
} 


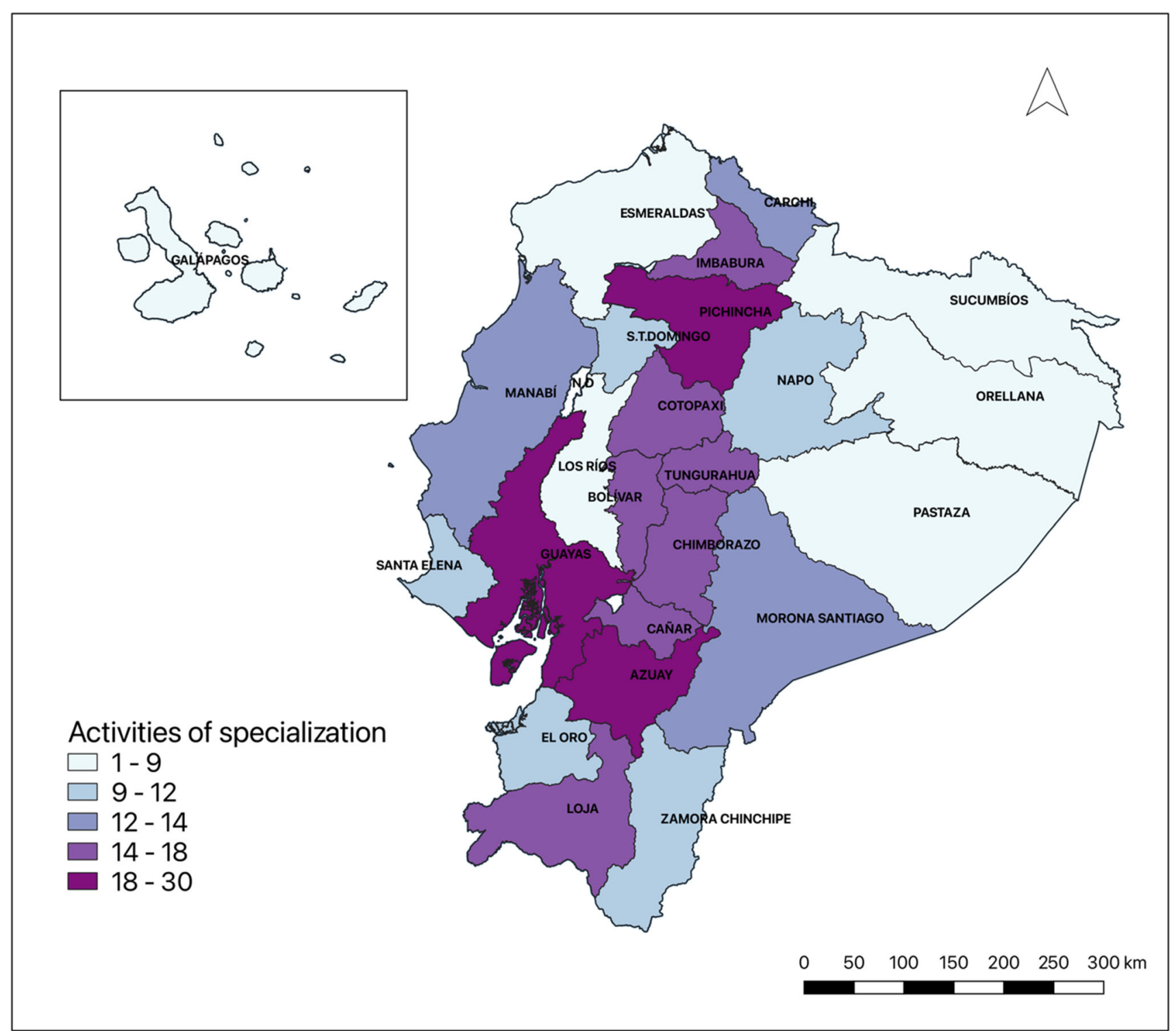

Fig. 3 Diversity Index, based on Gross Value Added, of Ecuador in 2015. This figure shows the sum of activities in which a province is specialized based on 46 economic sectors. A province is specialized

It should be noted, however, that general equilibrium models can respond to nonlinear structures, are sensitive to shifts in prices, incorporate behavior of households, consider substitution between inputs and import goods, and assume not only markets of goods but also markets of productive factors. But their assumptions of rationality in the context of a disaster have been called into question and seem to provide better results for indirect long-term evaluations (Rose and Liao 2005). The least used estimates are those of an econometric variety due to the availability of databases (cross-section or time series) and the geo-referencing of the activities and firms affected by the catastrophe. They may also fail to take second-order effects into account during estimation (Rose 2004). in a sector if its share in relation to the provincial GDP is higher than the national share. Data Source (CBE 2020)

\subsection{The Extended Miyazawa Model}

The versatility of input-output models is their adaptability for the evaluation of economic policies and shocks at a regional level. This requires the economic variables to be specified by region and productive sector, and the multipliers to be formulated consistently.

In these types of applications, the assumptions of technology, preferences, and generation and distribution of income are extended to sectoral and regional levels. For example, it is assumed that the demands for industry and households are inelastic with respect to price, regardless of the region where they are located. 
The extended Miyazawa model is formally set out below by considering the following extended specifications of the model. Let there be $K$ regions, $N$ productive sectors, and $H$ representative households. The input-output relationships in this economic system can be specified by the following matrix identity:

$$
\left(\begin{array}{l}
\boldsymbol{X} \\
\boldsymbol{Y}
\end{array}\right)=\left(\begin{array}{cc}
\boldsymbol{A} & \boldsymbol{C} \\
\boldsymbol{V} & 0
\end{array}\right) \times\left(\begin{array}{c}
\boldsymbol{X} \\
\boldsymbol{Y}
\end{array}\right)+\left(\begin{array}{l}
\boldsymbol{D} \\
\boldsymbol{G}
\end{array}\right)
$$

where:

- $\boldsymbol{X}=\left(\boldsymbol{x}^{(1)}, \boldsymbol{x}^{(2)}, \ldots, \boldsymbol{x}^{(\boldsymbol{r})}, \ldots, \boldsymbol{x}^{(\boldsymbol{K})}\right)^{\prime}$ is the total production matrix. Each $\boldsymbol{x}^{(r)} \in \mathbb{R}^{N}$ component is a vector showing the total production of $N$ sectors in the region $r$.

- $\boldsymbol{Y}=\left(\boldsymbol{y}^{(1)}, \boldsymbol{y}^{(2)}, \ldots, \boldsymbol{y}^{(\boldsymbol{r})}, \ldots, \boldsymbol{y}^{(\boldsymbol{K})}\right)^{\prime}$ is the endogenous income matrix (that is, wages and salaries). Each $\boldsymbol{y}^{(\boldsymbol{r})} \in$ $\mathbb{R}^{H}$ component is a vector showing the available income distribution between $H$ households in the region $r$.

- $\boldsymbol{A}=\left(\boldsymbol{a}^{(1,1)}, \boldsymbol{a}^{(1,2)}, \ldots, \boldsymbol{a}^{(\boldsymbol{r}, \boldsymbol{s})}, \ldots, \boldsymbol{a}^{(\boldsymbol{K}, \boldsymbol{K})}\right)$ is the technical coefficients matrix. Each $\boldsymbol{a}^{(r, s)} \in \mathbb{R}^{N} \times \mathbb{R}^{N}$ component is a submatrix showing the input requirements of $N$ sectors located in the regions $s$ from the $N$ sectors located in the region $r$.

- $\boldsymbol{C}=\left(\boldsymbol{c}^{(1)}, \boldsymbol{c}^{(2)}, \ldots, \boldsymbol{c}^{(\boldsymbol{r})}, \ldots, \boldsymbol{c}^{(\boldsymbol{K})}\right)^{\prime}$ is a consumption coefficients matrix. Each $\boldsymbol{c}^{(r)} \in \mathbb{R}^{N} \times \mathbb{R}^{H}$ component is a submatrix showing the income proportion used for the consumption of $N$ goods by $H$ households in the region $r$.

- $\boldsymbol{V}=\left(\boldsymbol{v}^{(1)}, \boldsymbol{v}^{(2)}, \ldots, \boldsymbol{v}^{(\boldsymbol{r})}, \ldots, \boldsymbol{v}^{(\boldsymbol{K})}\right)^{\prime}$ is a GVA proportions matrix. Each component $\boldsymbol{v}^{(r)} \in \mathbb{R}^{H} \times \mathbb{R}^{N}$ is a submatrix showing the proportion of GVA generated by $N$ sectors and its distribution between $H$ households in the region $r$.

- $\boldsymbol{D}=\left(\boldsymbol{d}^{(1)}, \boldsymbol{d}^{(2)}, \ldots, \boldsymbol{d}^{(\boldsymbol{r})}, \ldots, \boldsymbol{d}^{(\boldsymbol{K})}\right)^{\prime}$ is the aggregate demand matrix, excluding household consumption. Each $\boldsymbol{d}^{(\boldsymbol{r})} \in \mathbb{R}^{N}$ component is a vector showing the demand of $N$ final goods in the region $r$.

- $\boldsymbol{G}=\left(\boldsymbol{g}^{(1)}, \boldsymbol{g}^{(2)}, \ldots, \boldsymbol{g}^{(\boldsymbol{r})}, \ldots, \boldsymbol{g}^{(\boldsymbol{K})}\right)^{\prime}$ is the exogenous income matrix (that is, transfer payments and interests received). Each $\boldsymbol{g}^{(\boldsymbol{r})} \in \mathbb{R}^{H}$ component is a vector showing the income distribution between $H$ households in the region $r$.

It is evident that every matrix in model 1 (Eq. 1) is composed by blocks and each block is linked to a region. Based on this system, the following analytical solution can be obtained:

$$
\left(\begin{array}{c}
\boldsymbol{X} \\
\boldsymbol{Y}
\end{array}\right)=\left(\begin{array}{cc}
\boldsymbol{Z}\left(\boldsymbol{I}_{1}-\boldsymbol{C V Z}\right)^{-1} & \boldsymbol{Z C K} \\
\boldsymbol{K V Z Z} & \boldsymbol{K}
\end{array}\right) \times\left(\begin{array}{c}
\boldsymbol{D} \\
\boldsymbol{G}
\end{array}\right)
$$

where:

- $\boldsymbol{Z}=\left(\boldsymbol{I}_{1}-\boldsymbol{A}\right)^{-1}$ is the matrix of Leontief multipliers

- $\boldsymbol{K}=(1-\boldsymbol{V Z C})^{-1}$ is the matrix of income multipliers.

For the current study, model 1 was numerically solved by GAMS. ${ }^{8}$ In this model, the earthquake shock and the public assistance policy were introduced in the components, putting emphasis in the province of the earthquake epicenter, Manabí, as follows:

- The earthquake affects all sectors of Manabí proportionally according to their GDP share.

- The public assistance aid only affects the final demand of construction industry and wholesale/retail trade activities proportionally according to their GDP share.

\subsection{Input-Output Information by Sector and Region}

Application of the input-output model discussed in the previous section requires having the information about transactions carried out between any two sectors within a region or among regions to be identified. In Ecuador, the national accounts system has compiled a Supply-Use Table for the various purchase and sale transactions of the sectors of the economy nationwide. This table also contains the intermediate consumption totals at a regional level and by sector. It does not, however, contain transactions between one sector and another within a certain region. By virtue of this limitation, an extension of the RAS method ${ }^{9}$ for the estimation of this information is explained below. This extension considers a 4-dimensional information hypercube: the supplier sector $i$, the client sector $j$, the provider region $r$, and the client region $s$. Figure 4 illustrates the structure of this cube.

To construct this cube, the following elements were taken into account: the national aggregates from the

\footnotetext{
${ }^{8}$ GAMS (General Algebraic Modeling System) is a mathematical program of nonsymbolic source code that provides a series of mathematical tools designed to solve any type of optimization problem (linear programming, nonlinear, with integer variable, problems of mixed complementarity, among others), also making possible the management of databases for the implementation of the model.

9 The RAS method is a bi-proportional adjustment technique developed by Stone and Brown (1962) for the adjustment, balance, and updating of the Input-Output tables. Mathematically, the RAS method is a problem of maximum entropy, which calls for a reduction of the differences between the estimated proportions, organized in a matrix, and the proportions observed in external sources of information.
} 


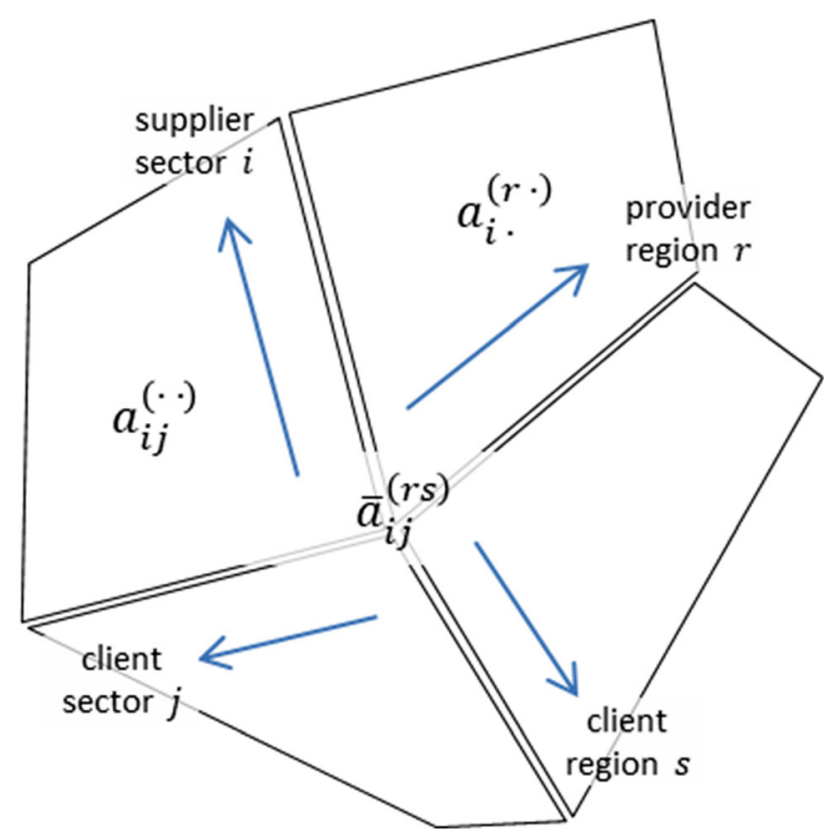

Fig. 4 Information cube for the RAS method extension

national accounts system: $\left\{a_{i j}^{(\cdot)}\right\}_{n \times n}$ and $\left\{a_{i \cdot}^{(r \cdot)}\right\}_{N}^{K}$; and the transactional annex from the Internal Revenue Service (IRS): $\left\{\bar{a}_{i j}^{(r s)}\right\}_{N \times N}^{K \times K}$.

The national aggregates $\left\{a_{i j}^{(\cdot)}\right\}_{n \times n},\left\{a_{i}^{(r \cdot)}\right\}_{N}^{K}$ are the statistics we seek to disaggregate at the regional level using external information. The expression $\left\{a_{i j}^{(\cdot)}\right\}_{N \times N}$ is the intermediate consumption between the productive sectors $i, j$ at the national level. The expression $\left\{a_{i}^{(r .)}\right\}_{N}^{K}$ represents total intermediate consumption made by the industry $i$ in the region $r$.

The transactional information from the IRS $\left\{\bar{a}_{i j}^{(r s)}\right\}_{N \times N}^{K \times K}$ paints a picture of intermediate consumption distribution by the regions $r, s$ and the industries $i, j$. Under this specification, the value of the $\left\{a_{i j}^{(r s)}\right\}_{N \times N}^{K \times K}$ coefficients for solving model 2 (Eq. 2) was found by the following constrained maximization problem:

$$
\begin{aligned}
& \max _{a_{i j}^{(r s)}}-\sum_{i=1}^{N} \sum_{j=1}^{N} \sum_{r=1}^{K} \sum_{s=1}^{K} a_{i j}^{(r s)} \log \left(\frac{a_{i j}^{(r s)}}{\bar{a}_{i j}^{(r s)}}\right) \\
& \sum_{r=1}^{K} \sum_{s=1}^{K} a_{i j}^{(r s)}=a_{i j}^{(\cdot)} \quad \forall 1 \leq i \leq N \quad \forall 1 \leq j \leq N
\end{aligned}
$$

$\sum_{j=1}^{N} \sum_{s=1}^{K} a_{i j}^{(r s)}=a_{i}^{(r .)} \quad \forall 1 \leq i \leq N \quad \forall 1 \leq r \leq K$

\subsection{Household Final Consumption by Sector and Region}

The household final consumption by sector and region was estimated similarly using an extension of the RAS method. This estimation was made in such a way that it remains consistent with the national aggregates provided by the System of National Accounts $\left\{c_{i}^{(\cdot)}\right\}_{N}$, and the data recorded in the Income and Expenditure Survey conducted by the National Institute of Statistics and Census $\left\{\bar{c}_{i}^{(r)}\right\}_{N}^{K}$. Here, $\left\{c_{i}^{(\cdot)}\right\}_{N}$ is the final consumption of the commodity $i$ at the national level and $\left\{\bar{c}_{i}^{(r)}\right\}_{N}^{K}$ contains the statistics of final consumption of the commodity $i$ in the region $r$.

Thus, the value of the $\left\{c_{i}^{(r)}\right\}_{N}^{K}$ coefficients was estimated using the following formulation:

$$
\begin{aligned}
& \max _{c_{i}^{(r)}}-\sum_{i=1}^{N} \sum_{r=1}^{K} c_{i}^{(r)} \log \left(\frac{c_{i}^{(r)}}{\bar{c}_{i}^{(r)}}\right) \\
& \sum_{r=1}^{K} c_{i}^{(r)}=c_{i}^{(\cdot)} \quad \forall 1 \leq i \leq N
\end{aligned}
$$

\section{Results}

This section shows the main characteristics of Ecuador's regional productive network estimated using the RAS method developed in the previous section. Based on this information, the effect of the earthquake on the Ecuadorian economy is estimated, using the Miyazawa model.

\subsection{Productive Network at the Regional Level}

Figure 5a displays the results of the estimation of intermediate consumption between provinces, and Fig. 5b displays household final consumption between sectors and provinces. The estimations allow regional multipliers in terms of intermediate and household final consumption calculation. This provides elements that may be essential for the regional analysis of the Ecuadorian economic structure, in a context highly subject to natural or anthropic shocks. In the case of Manabí, the most significant output linkages are associated with the provinces of Azuay, Esmeraldas, Guayas, and Pichincha (Fig. 5a, row 13). They add up to $68 \%$ of Manabi's total production. The most important input linkages are with the provinces of 


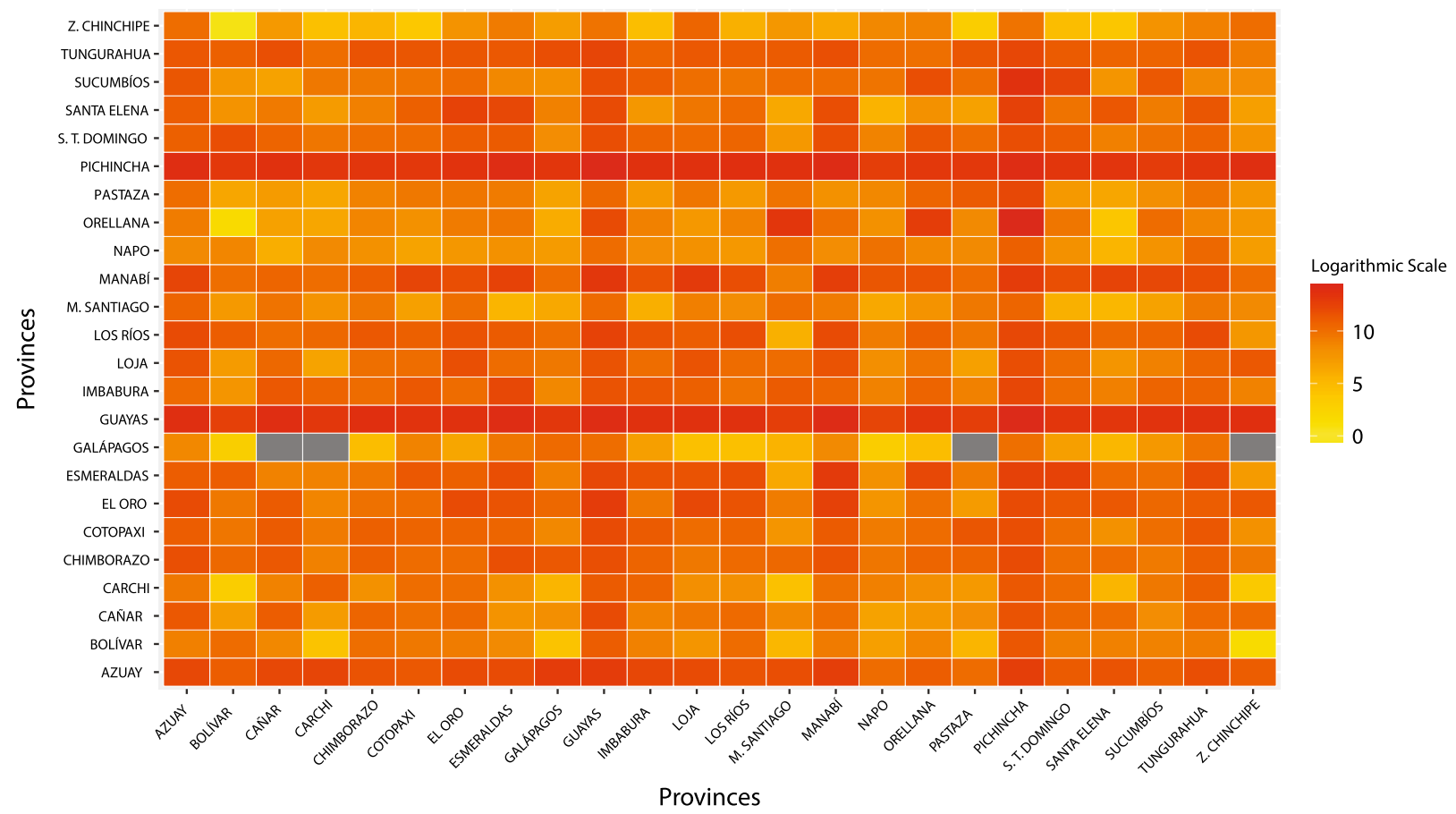

(a) Interprovincial intermediate consumption

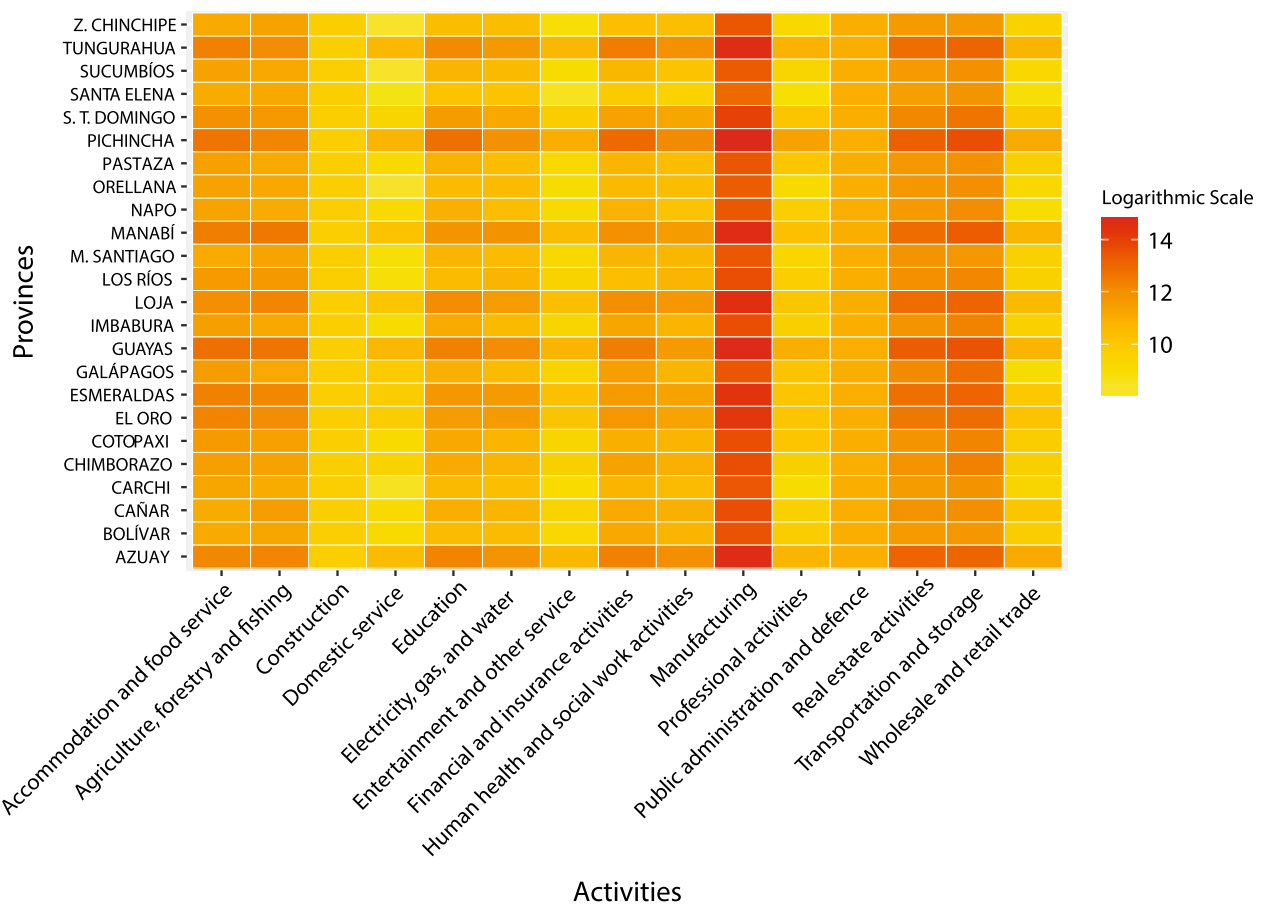

(b) Household final consumption

Fig. 5 Interprovincial intermediate consumption and household final consumption in Ecuador. a In the intermediate consumption for the 24 provinces of Ecuador and 16 economic activities estimated by RAS, the color highlights the magnitude of intermediate consumption. The higher the intensity of the color red, the higher the intermediate consumption is. b In the household final consumption for the 24 provinces of Ecuador and 16 economic activities estimated by RAS, the color highlights the magnitude of final consumption. The higher the intensity of the color red, the higher the final consumption is 


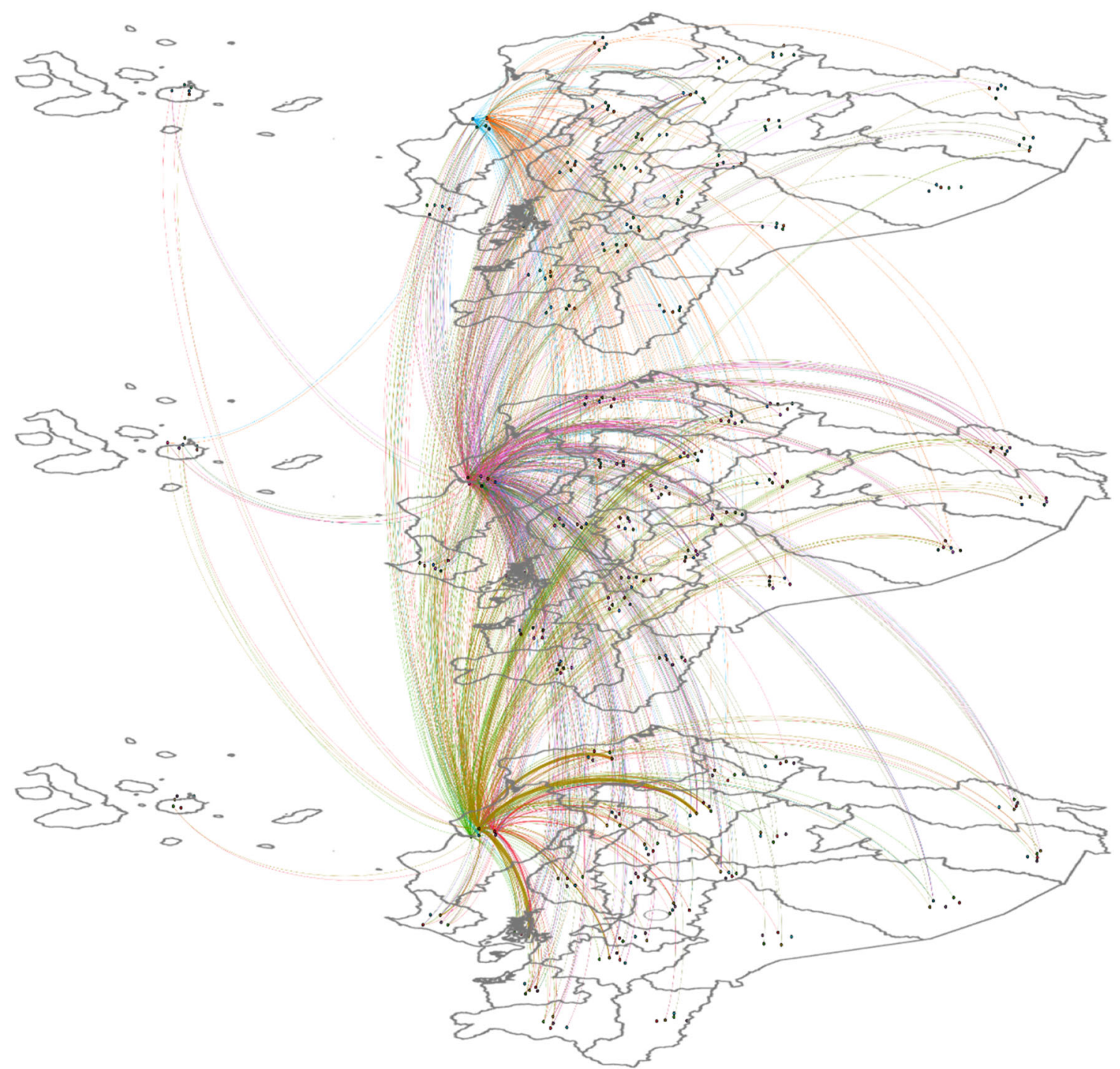

Fig. 6 Sales network of intermediate consumption from Manabí to all the other provinces over three 3D-layers of Ecuador's territorial map. From the top to the bottom, the first layer represents activities A, B, C, $\mathrm{D}$, and F; the second layer represents activities $\mathrm{G}, \mathrm{H}, \mathrm{I}, \mathrm{K}, \mathrm{L}$, and M;

Esmeraldas, Guayas, Loja, and Pichincha y Santa Elena (Fig. 5a, column 13). They amount to nearly $48 \%$ of Manabi's total intermediate consumption. Manabí provides mainly agricultural and manufactured goods and trade services for final consumption (Fig. 5b, row 13).

Figure 6 shows the sales network of intermediate consumption from Manabí to all the other provinces. The most significant linkages with other provinces are in activities and the third layer represents activities $\mathrm{O}, \mathrm{P}, \mathrm{Q}, \mathrm{R}-\mathrm{S}-\mathrm{U}$, and T. The color of the curves highlights the productive sector and their thickness represents the magnitude of economic flows. Orange: manufacturing; Purple: transportation; Green: construction

like manufacturing (orange), transportation (purple), and construction (green).

\subsection{Effects of the 2016 Earthquake}

For the calculation of the first partial negative effect, two official sources of information were taken as a reference to construct scenarios of the immediate negative impact. 


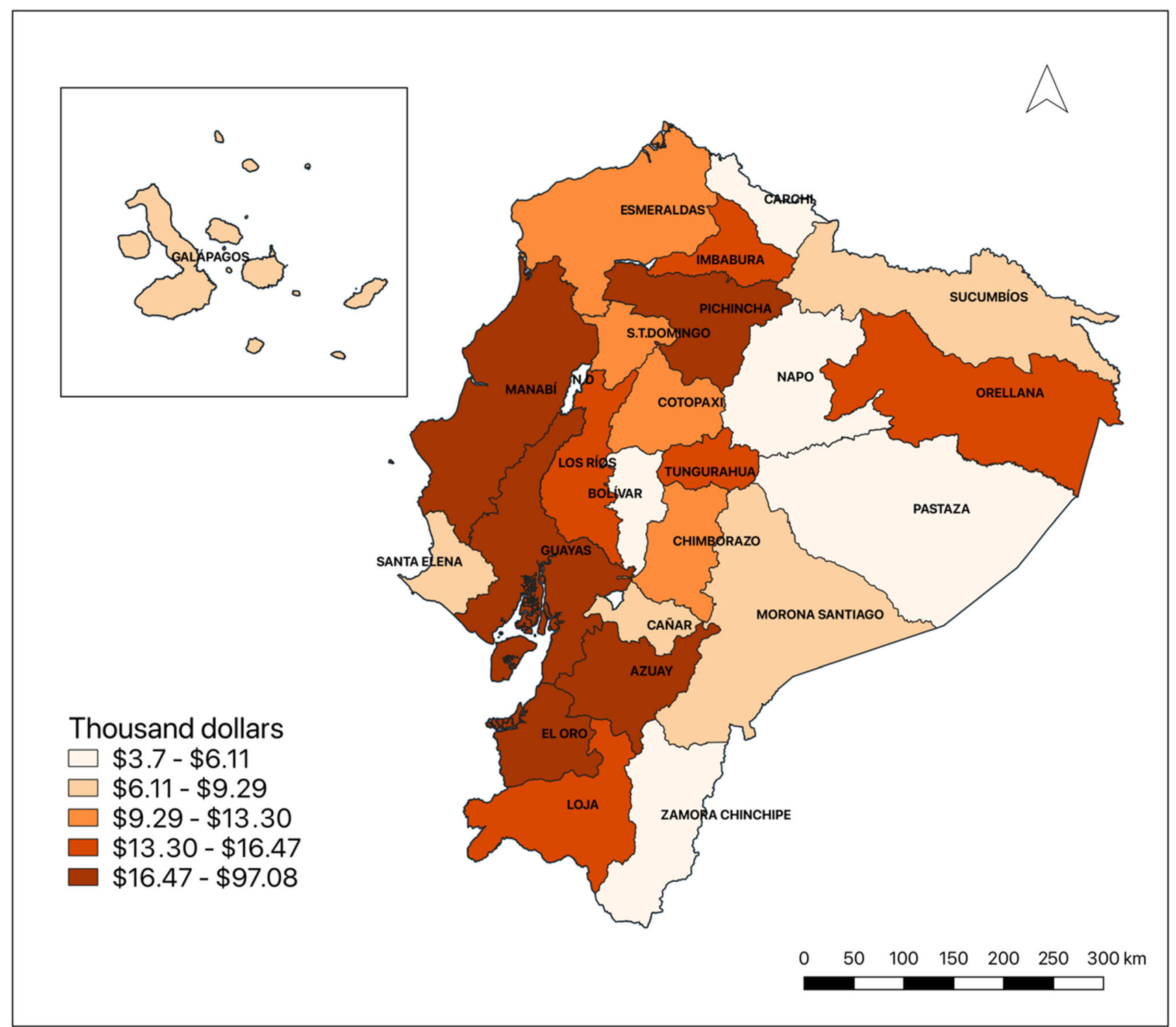

Fig. 7 Negative earthquake shock to the provinces. Changes by province only. This figure shows the losses in Gross Value Added (GVA) for the 24 provinces of Ecuador, as a consequence of the 2016

Information was provided by the Committee for Reconstruction and Productive and Employment Reactivation $(\text { CRPER })^{10}$ submitted on 30 September 2016 on its

\footnotetext{
${ }^{10}$ On 28 April 2016, as a result of the first evaluations with respect to the management by the public sector to address the aftermath of the earthquake, as well as for the planning for recovery, the Committee for Reconstruction and Productive and Employment Reactivation was created by executive decree by the President to coordinate between public and private entities to structure reconstruction plans, programs, and projects. The Committee, under the direction of the Vice President, was comprised of representatives of the National Secretariat for Planning, the ministries for the coordination of social development, production, employment, and competitiveness, and the Ministry of Internal and External Security, assembled by the prefect of Manabí and two mayors of the affected areas (El Comercio 2016).
}

earthquake under scenario a. The color highlights the magnitude of the GVA losses. The higher the intensity of the color orange, the higher the GVA loss

website. ${ }^{11}$ This information states that the estimated losses in final sales by economic activity, mainly concentrated in Manabí, were as follows. The trading sector lost USD 285 million; the manufacturing sector USD 92 million; the tuna industry 33.8 million; the shrimp industry 21.9 million; tourism 19.5 million; and in other sectors the loss was USD 102.1 million (CRPER 2016). The information published by the Central Bank of Ecuador, which was used in the quarterly and provincial sectoral national accounts, shows that the generation of value during the second quarter, that

\footnotetext{
11 https://www.reconstruyoecuador.gob.ec/wp-content/uploads/down loads/2016/10/Informe-Asamblea_SeTec-Reconstrucci\%C3\%B3n_ 20160830.pdf.
} 


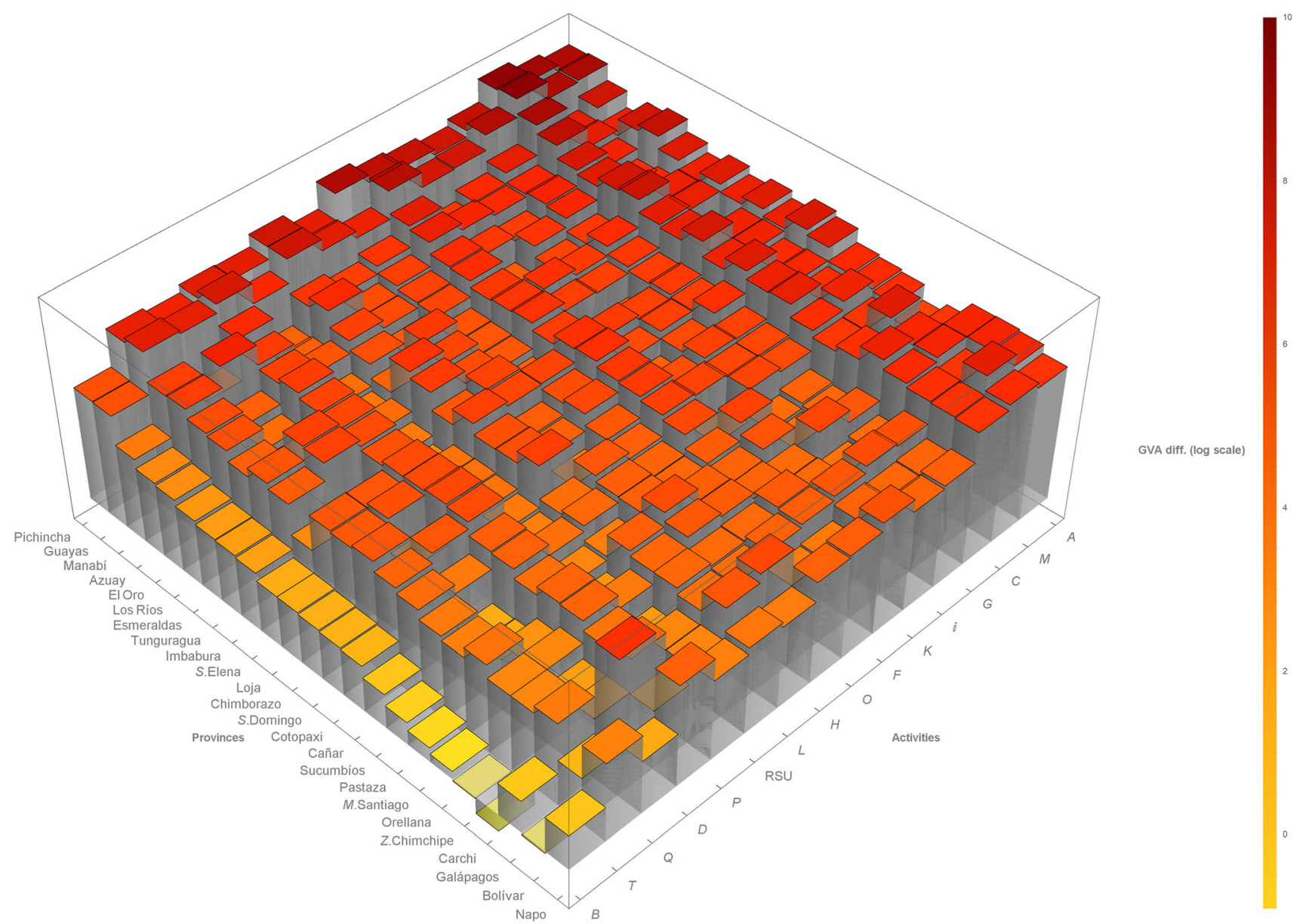

Fig. 8 Negative earthquake shock to the provinces. Changes by province and activity. This figure shows the losses in Gross Value Added (GVA) for the 24 provinces of Ecuador and in 16 economic activities, as a consequence of the 2016 earthquake under scenario a.

is, the quarter affected by the earthquake, was on average $25 \%$ of the generation of the total national value in the three previous years $(2013,2014$, and 2015). In that same period, Manabí's economy contributed to the national economy with $6 \%$ of the yearly value generation.

With these valuations, the immediate effects of the earthquake on the provinces and sectors of Ecuador were calculated under three scenarios describing a loss in Manabí's generation of yearly value: (a) 441.1 million; (b) 661.7 million; and (c) 882.3 million. In all three cases, the productive paralysis of the entire province was taken into account, weighting each sector through its share in provincial GDP.

Applying model 1 , the scenarios $\mathrm{a}, \mathrm{b}$, and $\mathrm{c}$ generate reductions in the national production of USD 862.96, 1293.39, and 1723.83 million, respectively. These results comprise the first partial effect due to earthquake. It should be noted that scenario a is the closest shock planned for by the Secretariat for Reconstruction, and it is represented in
The losses were ordered in descending order, from the upper corner of the graph to the bottom corner. The color highlights the magnitude of the GVA losses. The higher the intensity of the color red, the higher the GVA loss. The variations are intentionally ordered by value

Fig. 7. In general, the diffusion of the negative effects is low due to the low number of activities in which Manabí is specialized and as a result of the size and number of sectoral and spatial linkages. Here, the most affected provinces are Pichincha, Guayas, El Oro, and Azuay (Fig. 7), through activities like agriculture (A), professional activities (M), and manufacturing (C) (Fig. 8) .

\subsection{Effects of Public Assistance}

The estimate of the second positive partial effect of the earthquake is supported by the resources used for recovery between April and December 2016. These resources were acquired through financial aid from multilateral financial organizations and from the Law of Supportive Contribution for the Victims of the Earthquake in Ecuador. Among the most demanding measures of this law was a VAT increase to $14 \%$ during one year, a $3 \%$ tax on company profits, and a $0.9 \%$ tax on assets of over USD one million (both of which 


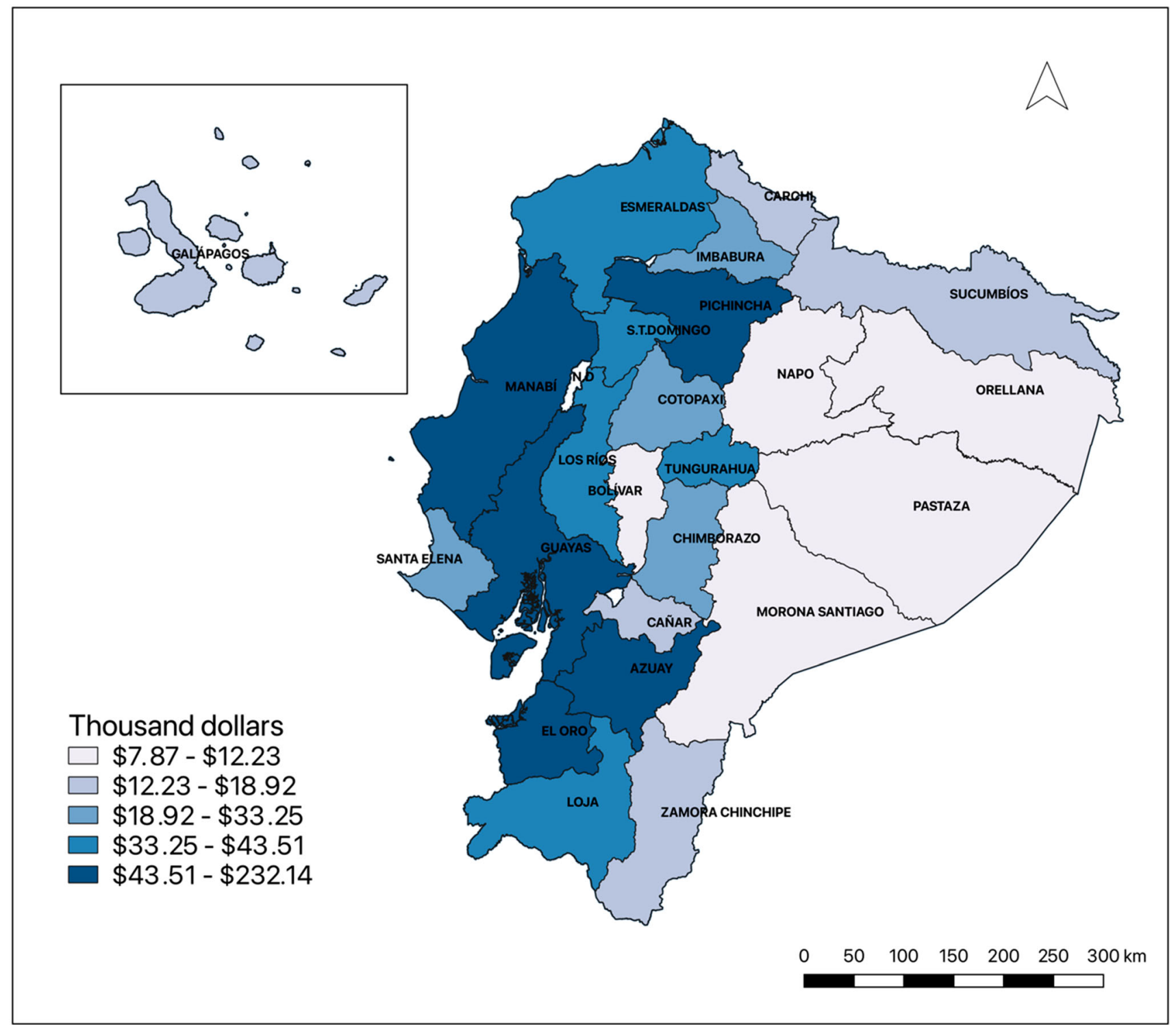

Fig. 9 Positive public assistance shock to provinces. Changes by province only. This figure shows the positive effects in Gross Value Added (GVA) for the 24 provinces of Ecuador, as a consequence of

were collected only once), the contribution of one day's worth of wages by workers whose incomes surpassed USD 1,000 per month, the sale of state assets, and a number of tax exemptions for those affected, intended to generate incentives for their recovery with respect to production. The Law of Supportive Contribution came into force in June, after it was approved by the National Assembly (El Comercio 2016). Other measures were also introduced, mainly by the public financial sector and the private banks. These measures included the cancellation of debts of impacted clients (El Telégrafo 2016).

In April 2017, in an interview with El Telégrafo, the Secretary for Reconstruction stated that nearly one billion dollars of the total amounts collected had been spent in the public assistance under scenario a. The color highlights the magnitude of the GVA gains. The higher the intensity of the color blue, the higher the GVA gain

2016. They were distributed with $70 \%$ in the construction sector and 30\% in other expenses relating to the support of the victims. Assuming the Secretary for Reconstruction's argumentation, three scenarios that increased the demand on the final sales of the construction industry and on wholesale and retail trade activities at the national level were considered: (a) USD 1,000 million; (b) USD 700 million; and (c) USD 400 million. Scenario a is the closest to that proposed by official entities.

According to model 1, scenarios a, b, and c increase the total national production by USD 1938.73, 1357.11, and 775.49 million, respectively. Figure 8 represents the effect of scenario a only. Here, the same provinces identified before-Guayas, Pichincha, Manabí, Azuay, and El Oro- 


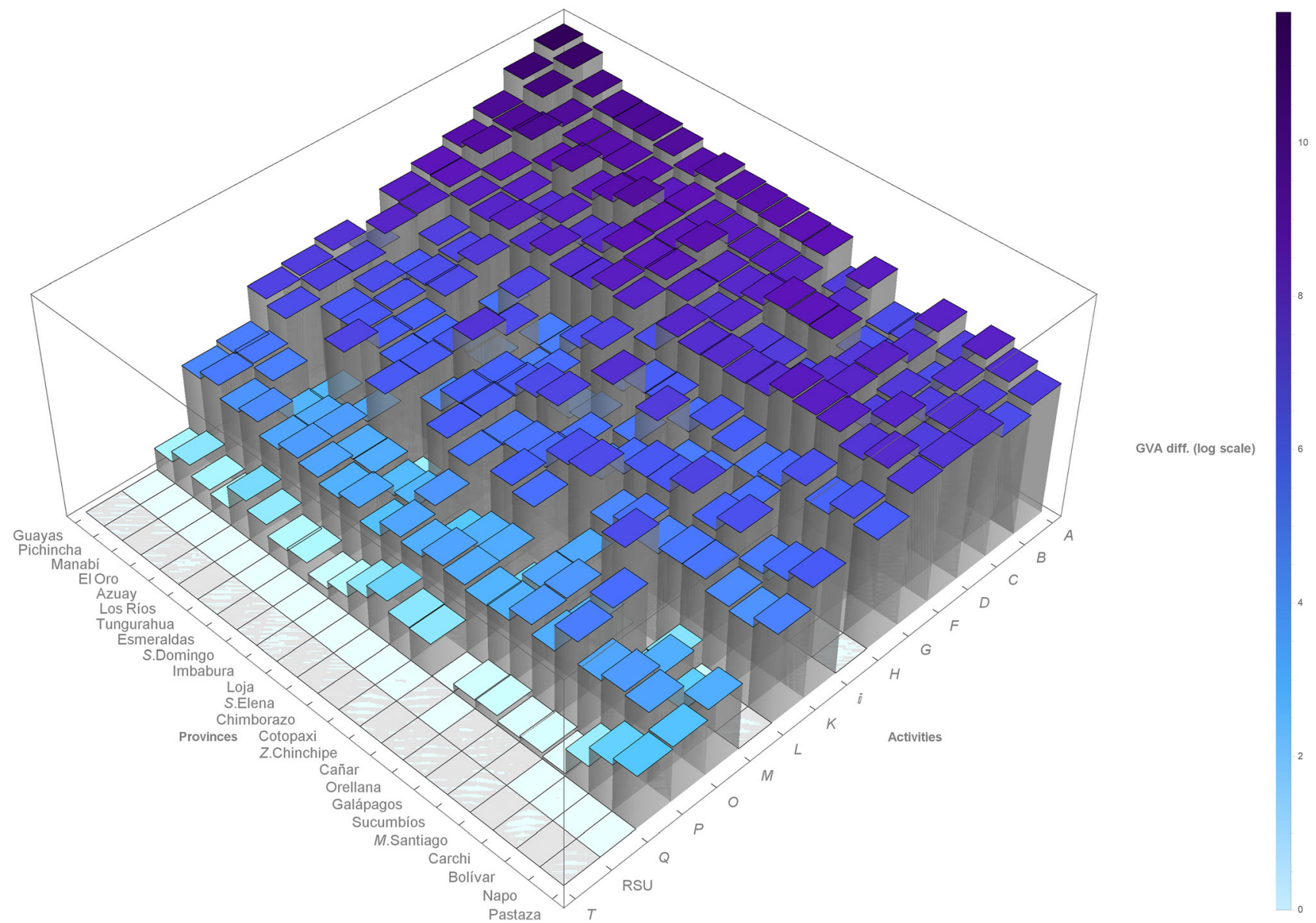

Fig. 10 Positive public assistance shock to provinces. Changes by province and activity. This figure shows the positive effects in Gross Value Added (GVA) for the 24 provinces and 16 economic sectors of Ecuador, as a consequence of the public assistance under scenario a.

benefited the most from the public assistance (Fig. 9). However, the shock expansion is driven not only by the agricultural and manufacturing activities but also by mining (Fig. 10).

Figures 11 and 12 display the net effects obtained by subtracting the positive from the negative effects only for scenarios closest to those indicated by the government agencies responsible for recovery. The provinces of Pichincha, Guayas, El Oro, and Azuay are the ones that achieved higher increases in their GVA after the public assistance, while Orellana, Sucumbíos, and Morona Santiago could not cancel out the negative effect propagated by the earthquake through the fiscal policy (Fig. 11). The main activities that spread aggregate positive shocks are agriculture, manufacturing, and mining, whereas activities corresponding to entertainment, domestic services, and human health diffuse the aggregate negative shocks (Fig. 12).
The gains were ordered in descending order, from the upper corner of the graph to the bottom corner. The color highlights the magnitude of the GVA gains. The higher the intensity of the color blue, the higher the GVA gain

\section{Conclusion}

The results of this model-consistent with the investigations of Albala-Bertrand (1993); Okuyama et al. (1999); Tol and Leek (1999); Skidmore and Toya (2002); and Loayza et al. (2012) - provide evidence that the net shortterm impact of the 16 April 2016 earthquake on the national accounts was not significant, and under some of the simulated scenarios based on the official information concerning the earthquake management, it may even have had a positive effect on the growth of the national product during the year 2016.

These results can be explained by two facts: (1) the economic setup of the most affected region-Manabí Province-shows that it is highly specialized in a few economic activities, mainly primary sector activities with limited economic linkages between sectors and with other provinces; and (2) the distribution across the economy of the positive impact of public spending - which took place in sectors and cities with a diverse economic 


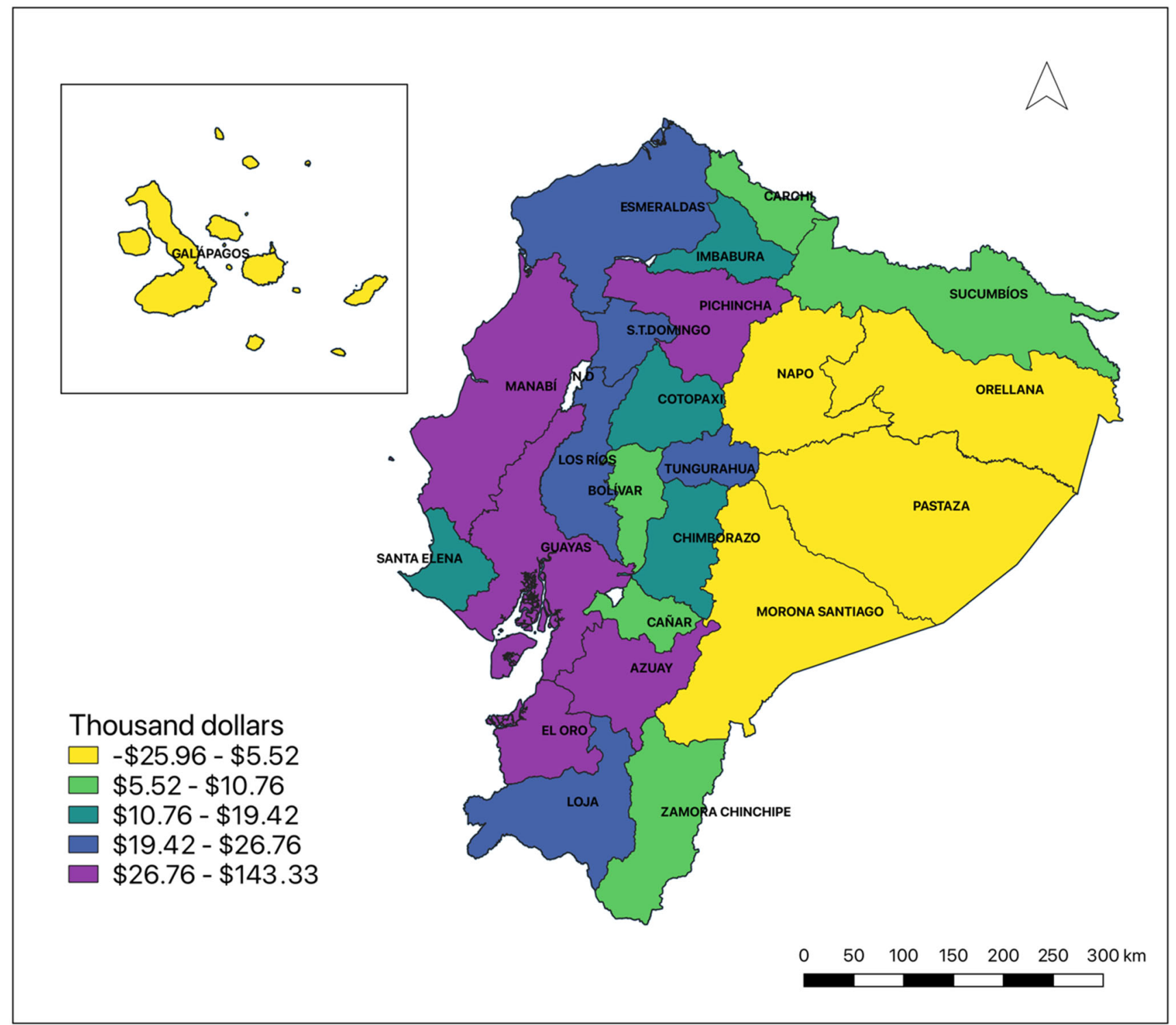

Fig. 11 Net effect of the earthquake and public assistance. Changes by province only. This figure shows the net effects in Gross Value Added (GVA) for the 24 provinces of Ecuador, as a consequence of both the negative effect of the earthquake and the positive shock of the public assistance under scenario a. The red-blue color gradation

performance-was characterized by the strongest multipliers and linkages in comparison with the ones related to where the epicenter was located.

The model proposed could have a relevant role in policy support, due to its usefulness for the design of an optimal economic recovery strategy based on sectors and areas that could bring the highest multipliers to the economy that is facing a negative exogenous shock. The simultaneous use of the Miyazawa approach and the RAS method could give insights into how to deal with data limitations, opening the possibilities of ex ante modeling in contexts with high risks specifies the sign and magnitude of the variation of GVA. If colored red, then the GVA decreases. The higher the intensity of the color red, the larger the decrease. If colored blue, then the GVA increases. The higher the intensity of the color blue, the larger the increase

of natural hazards and disasters and weak national account systems.

An important area of research could be the estimation of the effects of an event in other regions of the country-for example, Quito, which concentrates the highest amounts of population and economic activities in Ecuador and is highly vulnerable to natural hazard-related disasters. The model presented could give insights on how to mitigate the adverse economic impacts of natural hazard-related disasters in the Andean countries. 


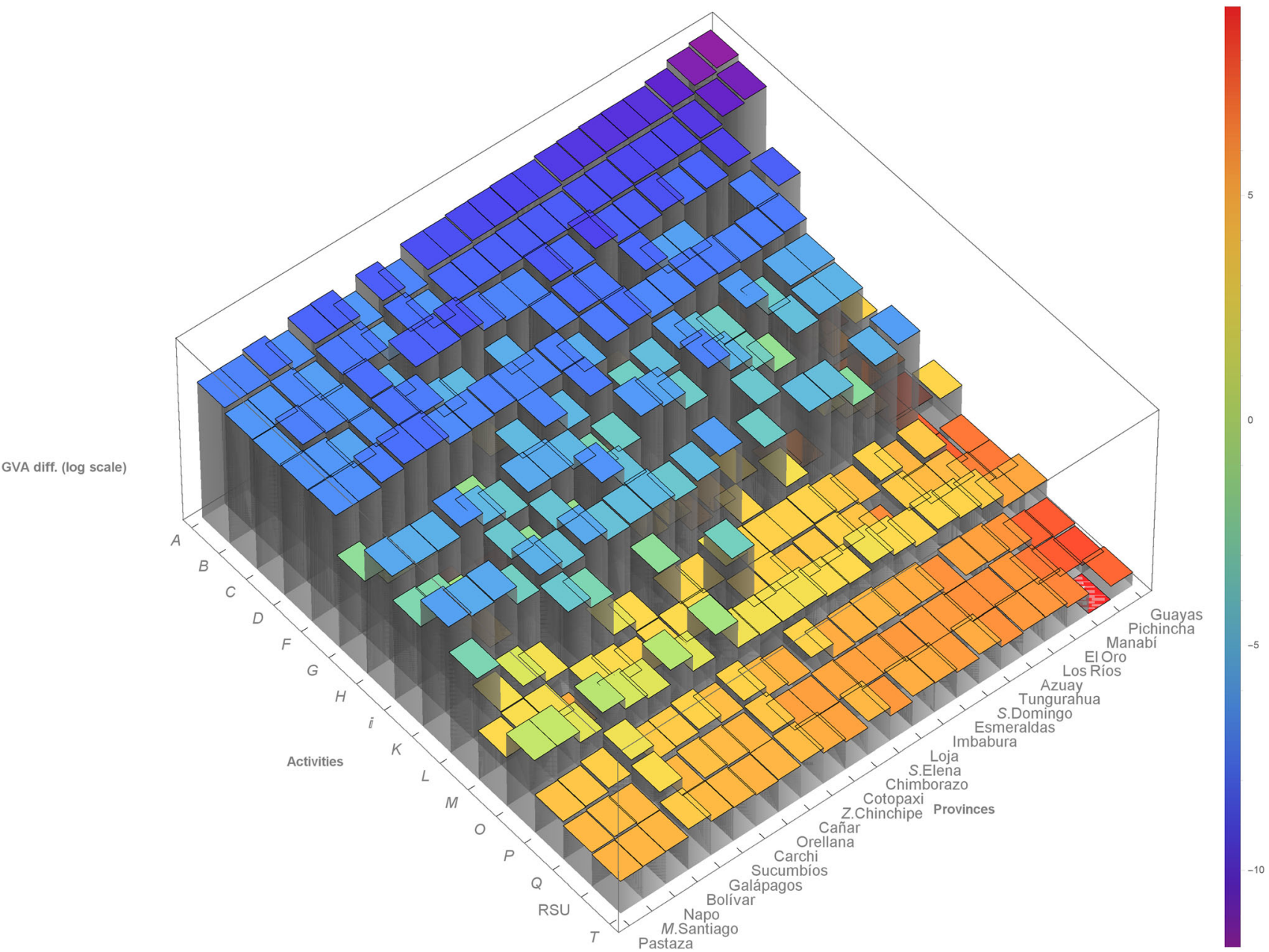

Fig. 12 Net effect of the earthquake and public assistance. Changes by province and activity. This figure shows the positive effects in Gross Value Added (GVA) for the 24 provinces and 16 economic sectors of Ecuador, as a consequence of both the negative effect of the earthquake and the positive shock of the public assistance under scenario a. The aggregate effects were ordered in descending order,

Acknowledgements We would like to express our appreciation to Rocio Bermeo and Rommel Montúfar for their support to the research and the social work of the School of Economics in the context of a natural hazard and disaster. We also would like to thank María Angélica Trujillo, Diego Gallarado, and Daniel Viola for their research assistance.

Open Access This article is licensed under a Creative Commons Attribution 4.0 International License, which permits use, sharing, adaptation, distribution and reproduction in any medium or format, as long as you give appropriate credit to the original author(s) and the source, provide a link to the Creative Commons licence, and indicate if changes were made. The images or other third party material in this article are included in the article's Creative Commons licence, unless indicated otherwise in a credit line to the material. If material is not included in the article's Creative Commons licence and your intended use is not permitted by statutory regulation or exceeds the permitted use, you will need to obtain permission directly from the copyright holder. To view a copy of this licence, visit http://creativecommons. org/licenses/by/4.0/. from the upper corner of the graph to the bottom corner. The red-blue color gradation specifies the sign and magnitude of the variation of GVA. If colored red, then the GVA decreases. The higher the intensity of the color red, the larger the decrease. If colored blue, then the GVA increases. The higher the intensity of the color blue, the larger the increase

\section{References}

Albala-Bertrand, J. 1993. Natural disaster situations and growth: A macroeconomic model for sudden disaster impacts. World Development 21(9): 1417-1434.

Avelino, A. 2017. Disaggregating input-output tables in time: The temporal input-output framework. Economic Systems Research 29(3): 313-334.

Avelino, A., and G. Hewings. 2017. The challenge of estimating the impact of disasters: Many approaches, many limitations and a compromise. The Regional Economics Applications Laboratory. REAL 17-T-1. http://real.illinois.edu/d-paper/17/17-T-1.pdf. Accessed 19 Apr 2021.

Beauval, C., H. Yepes, W. Bakun, J. Egred, A. Alvarado, and J. Singaucho. 2010. Locations and magnitudes of historical earthquakes in the Sierra of Ecuador (1587-1996). Geophysical Journal International 181(3): 1613-1633.

Bitrán, D. 2009. Methodology for the evaluation of socioeconomic impact of disasters (Metodología para la evaluación del impacto 
socioeconómico de los desastres). Serie Estudios y Perspectivas 108: 33 (in Spanish).

Bolton, P. 1991. The March 5, 1987, Ecuador Earthquakes: Mass wasting and socioeconomic effects. Washington, DC: The National Academies Press.

Carrión, A., I. Giunta, A. Mancero, and G. Jiménez (eds.). 2017. Postearthquake, risk management and international cooperation: Ecuador (Pos-terremoto, gestión de riesgos y cooperación internacional: Ecuador). Ecuador: Instituto de Altos Estudios Nacionales (IAEN) (in Spanish).

CBE (Central Bank of Ecuador). 2020. System of national accounts. https://www.bce.fin.ec/index.php/informacioneconomica/sectorreal. Accessed 9 May 2021 (in Spanish).

CRPER (Committee for Reconstruction and Productive and Employment Reactivation). 2016. Rebuild Ecuador Plan - Quarterly Report (Plan reconstruye Ecuador - Informe Trimestral). https://www.reconstruyoecuador.gob.ec/wp-content/uploads/ downloads/2016/10/Informe-Asamblea_SeTec-Reconstrucci\% C3\%B3n_20160830.pdf. Accessed 07 May 2021 (in Spanish).

Chang, S. 2000. Economic impacts. In The Chi-Chi, Taiwan, Earthquake of September 21, 1999: Reconnaissance report, technical report MCEER-00-0003, ed. G.C. Lee, and L. ChinHsiung, 101-114. Buffalo, NY: Multidisciplinary Center for Earthquake Engineering Research.

Chunga, K., M. Mulas, and M.F. Quiñonez. 2016. Geomorphologic and stratigraphic relationships as indicators of geologic hazard and paleoseismicity, central coast of Ecuador. In Proceedings of the 7th International INQUA Meeting on Paleoseismology, Active Tectonics and Archeoseismology (PATA), 30 May-3 June 2016, 59-62. Crestone, Colorado, USA. https://www.research gate.net/profile/Angelo-Constantine/publication/332330569_ Geomorphology_and_Stratigraphic_relationships_as_indica tors_of_Geologic_Hazard_and_Paleoseismicity_central_coast_ of_Ecuador/links/5cae1798299bf120975c3ef3/Geomorphologyand-Stratigraphic-relationships-as-indicators-of-GeologicHazard-and-Paleoseismicity-central-coast-of-Ecuador.pdf. Accessed 9 May 2021.

Cochrane, H. 1974. Social science perspectives on the coming San Francisco Earthquake: Economic impact, prediction, and reconstruction. Natural Hazard Research Working Paper No. 25. Boulder. CO: Institute of Behavioral Science, University of Colorado.

Dacy, D., and H. Kunreuther. 1969. The economics of natural disasters. New York: The Free Press.

ECLAC (Economic Commission for Latin America and the Caribbean). 1973. Report on the damage and repercussions of the earthquake in the city of Managua on the Nicaraguan economy (Informe sobre los daños y repercusiones del terremoto de la ciudad de Managua en la economía Nicaragüense). E/CN.12/AC.64/2/Rev.1. Santiago de Chile: Economic Commission for Latin America and the Caribbean (in Spanish).

El Comercio. 2016. Government creates a committee for the reconstruction and reactivation of production (Crean comité de reconstrucción y reactivación productiva). https://www.elcomer cio.com/actualidad/comitedereconstruccion-terremoto-ecuadorrafaelcorrea.html\#: :text=El\%20presidente\%20Rafael\%20Cor rea\%20firm\%C3\%B3,dej\%C3\%B3\%20m\%C3\%A1s\%20de\% $20600 \% 20$ fallecidos. Accessed 7 May 2021 (in Spanish).

El Telégrafo. 2016. The crisis due to the earthquake enters the second phase (La crisis por el sismo entra en segunda fase). https:// www.eltelegrafo.com.ec/noticias/ecuador/1/la-crisis-por-elsismo-entra-en-segunda-fase. Accessed 19 Apr 2021 (in Spanish).

Ellison, R., J. Milliman, and R. Roberts. 1984. Measuring the regional economic effects of earthquakes and earthquake predictions. Journal of Regional Science 24(4): 559-579.
Friesma, H.P., J. Caporaso, G. Goldstein, R. Linberry, and R. McCleary. 1979. Aftermath: Communities after natural disasters. Beverly Hills, CA: Sage.

Galbusera, L., and G. Giannopoulos. 2018. On input-output economic models in disaster impact assessment. International Journal of Disaster Risk Reduction 30: 186-198.

Haas, E., R. Kates, and M. Bowden. 1977. Reconstruction following disaster. Cambridge: MIT Press.

La Hora. 2016. VAT goes up to $14 \%$ for one year (El IVA sube al 14\% por un año), https://lahora.com.ec/noticia/1101937134/ noticia. Accessed 19 Apr 2021 (in Spanish).

Loayza, N., E. Olaberría, J. Rigolini, and L. Christiaensen. 2012. Natural disasters and growth: Going beyond the averages. World Development 40(7): 1317-1336.

Meli, R., D. Bitrán, and S. Santa Cruz. 2005. The Impact of Natural Disasters on Development: Basic Methodological Document for National Case Studies (El Impacto de los Desastres Naturales en el Desarrollo: Documento Metodológico Básico para Estudios Nacionales de Caso). New York and Santiago de Chile: United Nations and Economic Commission for Latin America and the Caribbean (in Spanish).

Munroe, T., and P. Ballard. 1983. Modeling the economic disruption of a major earthquake in the San Francisco Bay Area: Impact on California. The Annals of Regional Science 17(3): 23-40.

National Academy of Sciences. 1975. Earthquake prediction and public policy. Washington, DC: Printing and Publishing Office, National Academy of Sciences.

National Research Council. 1999. Committee on assessing the costs of natural disasters, the impacts of natural disasters: A framework for loss estimation. Washington, DC: National Academy Press.

National Secretariat for Planning and Development (Secretaría Nacional de Planificación y Desarrollo). 2016. Evaluation of the reconstruction costs (Evaluación de los costos de reconstrucción) (in Spanish).

Okuyama, Y. 2004. Modeling spatial economic impacts of an earthquake: Input-output approaches. Disaster Prevention and Management 13(4): 297-306.

Okuyama, Y. 2008. A critical review of methodologies on disaster impact estimation. Graduate School of International Relations, International University of Japan, Niigata, Japan. https://www. coursehero.com/file/71545967/Okuyama-Critical-Reviewpdf/. Accessed 7 May 2021.

Okuyama, Y., and S. Chang. 2004. Modeling spatial and economic impacts of disasters. Berlin: Springer Science \& Business Media.

Okuyama, Y., M. Sonis, and G.J.D. Hewings. 1999. Economic impacts of an unscheduled, disruptive event: A Miyazawa multiplier analysis. In Understanding and interpreting economic structure, ed. G.J.D. Hewings, M. Sonis, M. Madden, and Y. Kimura, 113-143. Heidelberg: Springer.

Oosterhaven, J., and M. Bouwmeester. 2016. A new approach to modeling the impact of disruptive events. Journal of Regional Science 56(4): 583-595.

Rose, A. 2004. Economic principles, issues, and research priorities in hazard loss estimation. In Modeling spatial and economic impacts of disasters, ed. Y. Okuyama, and S.E. Chang, 13-36. New York: Springer.

Rose, A., and S. Liao. 2005. Modeling regional economic resilience to disasters: A computable general equilibrium analysis of water service disruptions. Journal of Regional Science 45(1): 75-112.

Scawthorn, C., B. Lashkari, and A. Naseer. 1997. What happened in Kobe and what if it happened here? In Economic consequences of earthquakes: Preparing for the unexpected, ed. B.G. Jones, 15-49. Buffalo: National Center for Earthquake Engineering Research.

Skidmore, M., and H. Toya. 2002. Do natural disasters promote longrun growth?. Economic Inquiry 40(4): 664-687. 
Stone, R., and J. Brown. 1962. Output and investment for exponential growth in consumption. Review of Economic Studies 29(3): 241-245.

Tol, R., and F. Leek. 1999. Economic analysis of natural disasters. In Climate change and risk, ed. T. Downing, A. Olsthoorn, and R. Tol, 308-327. London: Routledge.

Toulkeridis, T., K. Chunga, and W. Renteria. 2017. The 7.8 Mw Earthquake and Tsunami of the 16th April 2016 in Ecuador: Seismic evaluation, geological field survey and economic implications. Science of Tsunami Hazards 36(4): 197-242.

Wright, J., P. Rossi, S. Wright, and E. Weber-Burdin. 1979. After the clean-up: Long-range effects of natural disasters. Beverly Hills, CA: Sage.

Wright, J.D., and P.H. Rossi. 1981. Social science and natural hazards. Cambridge, MA: Abt Books.

Wu, J., N. Li, S. Hallegatte, P. Shi, A. Hu, and X. Liu. 2012. Regional indirect economic impact evaluation of the 2008 Wenchuan Earthquake. Environmental Earth Sciences 65(1): 161-172.
Ye, L., H. Kanamori, J. Avouac, L. Linyan, K. Cheung, and T. Lay. 2016. The 16 April 2016, $M_{W} 7.8\left(M_{S} 7.5\right)$ Ecuador earthquake: A quasi-repeat of the $1942 \mathrm{M}_{\mathrm{S}} 7.5$ earthquake and partial rerupture of the $1906 \mathrm{M}_{\mathrm{S}} 8.6$ Colombia-Ecuador earthquake. Earth and Planetary Science Letters 454: 248-258.

$\mathrm{Yu}$, K.D.S., R.R. Tan, and J.R. Santos. 2013. Impact estimation of flooding in Manila: An inoperability input-output approach. In Proceedings of the 2013 IEEE Systems and Information Engineering Design Symposium (SIEDS), 26 April 2013, Charlottesville, Virginia, USA, 47-51.

Zapata, R., R. Caballero, E. Jarquín, J. Perfit, and S. Mora. 2000. A matter of development: How to reduce vulnerability in the face of natural disasters. Washington, DC and Santiago de Chile: Inter-American Development Bank and Economic Commission for Latin America and the Caribbean. 